\title{
Hybrid (Ag)ZnO/Cs/PMMA nanocomposite thin films
}

\author{
Ghisman Plescan Viorica ${ }^{\mathrm{a}}$, Viorica Musat ${ }^{\mathrm{a},{ }^{*}}$, Ana Pimentel ${ }^{\mathrm{b}}$, Tomas R. Calmeiro ${ }^{\mathrm{b}}$, Emanuel Carlos ${ }^{\mathrm{b}}$, \\ Liliana Baroiu $^{\mathrm{c}}$, Rodrigo Martins ${ }^{\mathrm{b}}$, Elvira Fortunato ${ }^{\mathrm{b}, * *}$ \\ a Centre of Nanostructures and Functional Materials-CNMF, Department of Materials Science and Engineering, Faculty of Engineering, "Dunărea de Jos" University of Galati, \\ Romania \\ ${ }^{\mathrm{b}}$ Materials Science Department, CENIMAT/I3N and CEMOP/UNINOVA, Faculty of Sciences and Technology, New University of Lisbon, Campus de Caparica, 2829-516, \\ Caparica, Portugal \\ " Faculty of Medicine and Pharmacy, "Dunărea de Jos" University of Galati, Romania
}

\section{A R T I C L E IN F O}

Article history:

Received 25 January 2019

Received in revised form 27 June 2019

Accepted 29 June 2019

Available online $\mathrm{xxx}$

Keywords:

(Ag) $\mathrm{ZnO} / \mathrm{Cs} / \mathrm{PMMA}$ hybrids

Dielectric films

Modified sol-gel method

Optical properties

Electrical properties

Antimicrobial properties

\begin{abstract}
A B S T R A C T
Combining well known oxide materials with biocompatible polymers such as chitosan (Cs) and antimicrobial agents such as Ag can bring new functionalities to materials for electronics and lead to new border applications in the field of stretchable wearable bioelectronics and drug delivery systems. The paper reports on new hybrid thin films based on zinc oxide $(\mathrm{ZnO})$ and $\mathrm{Ag}: \mathrm{ZnO}$ nanoparticles dispersed in chitosan and incorporated in poly(methyl methacrylate) (PMMA) matrix by a modified sol-gel method. The structure, morphology, optical, electrical and antimicrobial properties of the obtained hybrid $\mathrm{ZnO} / \mathrm{Cs} / \mathrm{PMMA}$ and Ag:ZnO/Cs/PMMA thin films have been investigated. For electric characterization, current-voltage, capacitance-voltage and dielectric constant-frequency curves of the one and two-layers hybrid thin films deposed in MIS structure have been recorded. The dielectric constant values between 9.5 and 14.9 at $20 \mathrm{kHz}$, in addition with low surface roughness, optimal optical transmittance in visible and near-infrared region of about $90 \%$ and optical band gap $\left(E_{g}\right)$ values between 3.543 and $3.737 \mathrm{eV}$, indicate high potential applications of the obtained hybrid films in transparent bioelectronics. The antimicrobial activity of the hybrid sols used for the film's deposition and the resulted thin films have been investigated using the paper disc method on Mueller-Hinton agar against Gram negative $E$. coli and Gram positive $S$. aureus bacteria. Ag: $\mathrm{ZnO} / \mathrm{Cs} / \mathrm{PMMA}$ films showed good antimicrobial activity against $S$. aureus and $E$. coli.
\end{abstract}

(C) 2019

\section{Introduction}

The integration of nanotechnologies and nanoengineered materials into electronic products emerged the transparent and flexible electronic and electrophotonic (TFE) applications, such as flexible displays, solar cells, light emitting diodes (LEDs), (bio)sensors and wearable devices [1-4]. The development of transparent thin film transistors (TFTs) has been crucial for yielding these TFE applications [2,3]. Since 2004, when the first transistor with semiconductor metal oxide channel (MOTFT) has been successfully completed [5] and so far, the full-oxide TFT has been achieved, the MOTFTs demonstrated the best electrical performance into transparent and flexible devices $[2,3]$. Nowadays the research for alternative materials in the fabrication of transparent and flexible electronic devices based on TFTs have been focused on the development of large area processing multifunctional thin films $[1-3,6]$. The bottom-up approaches from solutions have enabled low-cost large area transparent and flexible transistors by deposition below $200^{\circ} \mathrm{C}$ of both semiconductor and dielectric thin films on different substrates $[3,6,7]$.

\footnotetext{
* Corresponding author.

** Corresponding author.

Email addresses: viorica.musat@ugal.ro (V. Musat); elvira.fortunato@fct.unl.pt (E. Fortunato)
}

For the last decade, an important progress has been also obtained in the development of organic field effect transistors (OFETs) characterized by low-voltage operation, which are well-suited for stretchable and wearable electronics and bioelectronics (display devices, radio frequency identification tags (RFIT), wearable electronic patches) $[8,9]$. For organic transparent and flexible electronics in various devices, poly(methyl methacrylate) (PMMA) has been evaluated as an option for the dielectric gate due to its thermal stability, chemical resistance, mechanical flexibility and high resistivity, low cost and good dielectric constant $[6,7]$. PMMA has been used into polymer blend dielectrics or ion-gel dielectrics gates to improve the dielectric characteristics and the surface morphology for flexible OFETs applications [3]. The use of organic semiconducting polymers has expanded from flexible displays to bidirectional flexible large-area organic circuits, which can form active-matrix of flexible and stretchable sensors, with low power consumption and reduced amount of connecting wiring, known as "artificial skins" [10] and other bioapplications [11]. Organic electronics enables printing technologies to obtain multifunctional materials over flexible and large areas substrates with reduced cost and easy integration into devices [12].

At the moment, the most efficient OFETs are fabricated with inorganic gate dielectrics characterized by high dielectric constant and high-voltage operation. Many researches have been focusing on decreasing the operation-voltage of the high performance OTFTs, in order to get compatibilization with wearable bioelectronics devices, by 


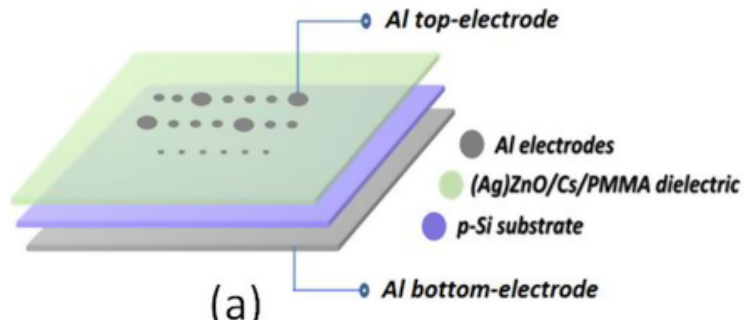

(a)

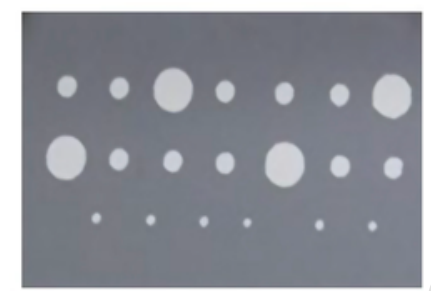

(b)

Fig. 1. Schematic cross-section (left) and top-view optical micrograph image (right) of the metal-insulator-semiconductor (MIS) structure.


Fig. 2. SEM images of $\mathrm{ZnO}$ (a) and $\mathrm{Ag}: \mathrm{ZnO}$ (b) NPs used for the preparation of hybrid thin films.
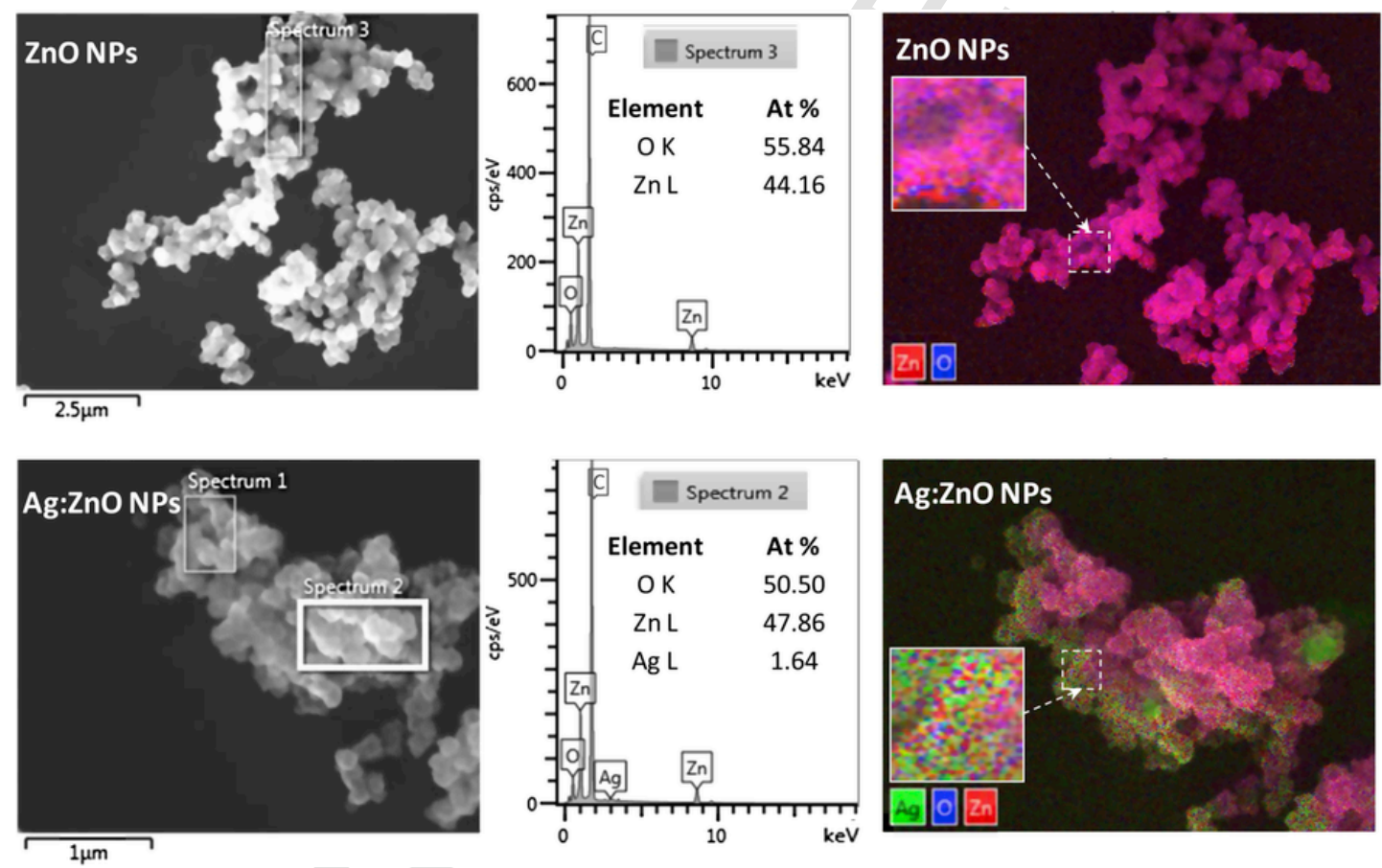

Fig. 3. SEM-EDX spectra and elemental mapping of $\mathrm{ZnO}$ and $\mathrm{Ag}: \mathrm{ZnO}$ NPs used for the preparation of hybrid thin films.

combination of inorganic and organic dielectrics for the fabrication of hybrid dielectric gates. For this purpose, polymer-based dielectric hybrid materials obtained through mixing, cross-linking and incorporation of nanoparticles (NPs) as inorganic fillers are being investigated $[3,6-8]$. The integration of these hybrid nanomaterials based on metal oxide, metals and polymers into electronics by low-temperature processing from solutions has emerged the new generations of flexible and stretchable electronic (FSE) devices $[3,6-8]$ with new application in various fields. The Tobin's group reviewed the recent advances in the fabrication of thin-films-based TFTs including different types (polymeric, inorganic, polyelectrolyte or hybrid) gate dielectrics integrated with FSE-compatible semiconductors nanomaterials such as metal oxides, quantum dot arrays, polyelectrolytes, carbon nanotubes or graphene [3]. Hybrid $\mathrm{ZrHfO}_{2}-\mathrm{PMMA}$ films gate dielectric obtained by sol-gel process at low temperature $\left(200^{\circ} \mathrm{C}\right)$ for indium gallium zinc oxide (IGZO)-based TFTs were reported by Syamala Rao et al. The $108 \mathrm{~nm}$ thick hybrid films showed good dielectric behavior and operation-voltage below 6V [13]. Lately, Meza-Arroyo et al. 

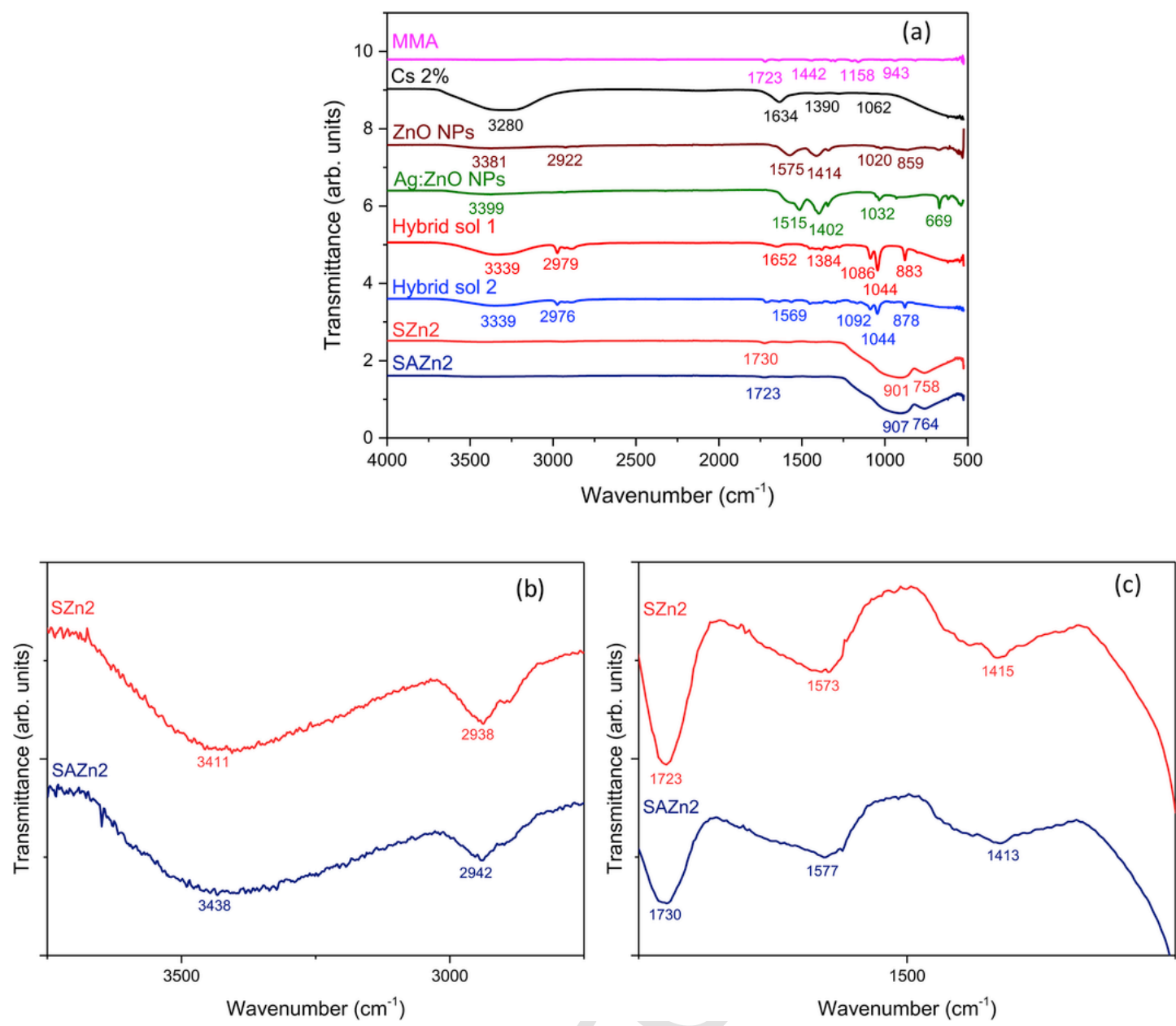

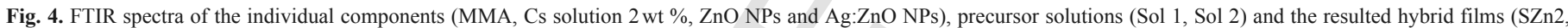
SAZn2) (a), and details from the spectra of the hybrid films (b-c).

have reported also low temperature sol-gel synthesis of transparent $\mathrm{Al}_{2} \mathrm{O}_{3}$-PMMA hybrid films tested as gate dielectric for TFTs. The obtained hybrid films showed operating voltage under $8 \mathrm{~V}$ [14]. Choudhary et al. reported the use of $\mathrm{ZnO}$ nanoparticles in hybrid films based on PVA-PVP blend matrix polymer nanocomposites, proposed as novel nanodielectrics substrate and electrical insulators for next generation of flexible optoelectronics and gas sensors devices [15]. The PMMA/ZnO nanocomposite hybrid system has also been synthesized and investigated for potential applications in different domains such as optics, photonics and electronics [16]. $\mathrm{ZnO}$ is a well-known multifunctional n-type semiconductor filler with a wide band gap $(3.4 \mathrm{eV})$ and large exciton binding energy which makes it useful in a broad range of applications like optoelectronic devices, dye-sensitized solar cells, (photo)catalysts and sensors [17]. Doping of $\mathrm{ZnO}$ with convenient elements is a method for creating p-type states and engineering optical, electrical and magnetic properties. Silver has been reported as the best candidate in this respect due to its high solubility, larger ionic size, and minimum orbital energy [18]. In a recent study, Meeporn et al. have reported the use of $\mathrm{Ag}$ in complex hybrid flexible dielectric films for advanced electronics [19]. In addition, silver is a well-known antimicrobial agent [20] that can bring new functionalities to hybrid materials for electronics and can lead to new frontier applications.

Most recently, biopolymers, which have very important features such as thermal stability, solution processability at room temperature and biodegradability, gain relevance as innovative material towards low-cost printed electronics [3,21-24]. Ji et al. reported transparent and high conductive cellulose-silver hybrid films with very good mechanical and thermal stability and high potential to be used as cover layer of flexible touchscreen panels in smart watches and fitness or medical monitors, without affecting touch performance [21]. In 2011 Zhou et al. published a first report on the use of chitosan-based materials in electronics, as dielectric in a hybrid indium tin oxide (ITO)-based thin film transistor. They attributed the high performance of the obtained TFTs to the high gate dielectric capacitance induced by the electric-double-layer effect, created by Cs proton mobility, at the interface between dielectric and ITO semiconducting oxide [25]. Along with other renewable materials, such as paper, silk and biodegradable polymers [22], chitosan has been extensively studied for developing flexible and lightweight biodegradable printed electronics with low production costs for applications such as consumer electronics and disposable systems $[3,9,22]$. The second most abundant polymer in nature after cellulose, chitosan and derivatives offer the possibility for fabrication of biocompatible devices that could operate in biologically relevant media, such as smart biosensing and preventive medical care $[22,24-26]$. Due to its protonic electrical conduction, $\mathrm{Cs}$ is an important candidate for functional bioelectronic material. Among other polysaccharides, Cs solid-state electrolytes have been demonstrated as effective gate dielectrics in TFTs [24-26]. In 2016, Morgado et al. published a paper related to the use of Cs in ultralow operation voltage OTFTs with organic semiconductor (pentacene) channel, concluding that self-standing chitosan films are very interesting 



Fig. 5. TG-DSC thermogram of the $\mathrm{ZnO} / \mathrm{Cs} / \mathrm{MMA}$ (hybrid sol 1) and $\mathrm{Ag}: \mathrm{ZnO} / \mathrm{Cs} /$ MMA (hybrid sol 2).

dielectrics for organic TFTs and can be used in organic electronics for a wide range of applications, ranging from disposable systems to biosensors and other biomedical applications [24]. In the same period, Feng et al. published a paper about a new-concept multi-gate electric double layer transistor with ultralow operation voltages, based on solution-processed graphene oxide/chitosan composite films as excellent proton conducting electrolyte with potential applications in two-terminal synaptic devices [26].

All the components investigated in this paper for hybrid thin films (Ag, ZnO NPs, Cs and PMMA) demonstrated the capabilities to act as functional or multifunctional (nano)material not only in biosensors [22-28], but also into drug delivery systems [29-33]. As drug carri- ers, nanoparticles offer many advantages such as adjustable size and shape, larger active surface area with enhanced stability and high-density at the ligand attachment at its surface and controlled intracellular drug-delivery [27,29,31]. Adapting the shape and size at nanoscale, which allow nanoparticles to interact with biomolecules within or on the cell surface and enabling them to affect cellular responses in a dynamic and selective manner, is a new approach to designing new anti-cancer agents and new type of interaction with tumor tissue and its subsequent retention, process known as enhanced permeation and retention (EPR) effect [34]. In addition, due to its known excellent antibacterial, antiviral, antifungal and antioxidant properties, Ag nanoparticles drug carriers are considered to be multifunctional drug delivery systems that offer special advantages, as transmembrane delivery without harsh transfection agents and protection of the attached therapeutics from degradation [21,31,34-36]. The antimicrobial silver nanoparticles were investigated as efficient delivery vehicle for drug against infection [35] or anticancer therapeutic agents (doxorubicin and alendronate compounds) with improved therapeutic effect with reduced side effects when administered into the body [36]. $\mathrm{ZnO}$ nanoparticles and $\mathrm{ZnO}$ /PMMA demonstrated a high degree of cancer cell selectivity [29,37]. Systems that are less toxic, more biocompatible and likely to be taken up by cells have been considered for drug delivery applications. For this purpose, coverage or incorporation of nanoparticles with different biocompatible polymers is the most appropriate approach. Chitosan has demonstrated the capability to act as biocompatible and biodegradable drug-carrier with slow and controlled release of different active species, based on its ability to chelate metal ions and to graft polymers. Based on the capability of chitosan and PMAA chains to link metal ions and quantum dots, $\mathrm{W}$. Wu et al. reported the preparation of a new class of chitosan-based hybrid nanogels by in-situ immobilization of photoluminescent CdSe quantum dots and anticancer drug in covalently cross-linked chitosan/PMAA hybrid nanogels with controlled release of anticancer drug in biological medium [38]. The most important mechanisms related to antimicrobial activity of nanomaterials are the photocatalytic production of reactive oxygen species (ROS) that damage the cell components $\left(\mathrm{TiO}_{2} \mathrm{NPs}, \mathrm{ZnO}\right.$ NPs, Ag NPs), the deterioration of bacterial cell membrane (peptides, chitosan, carboxyfullerene, carbon nanotubes, ZnO NPs and Ag NPs), the interruption of energy transduction (Ag NPs, fullerene NPs) and the inhibition of enzymes activity and DNA synthesis (chitosan). In terms of nanomaterials, due to high surface area with high defect concentration, the ROS generation mechanism, that induce oxidative stress and intracellular release of dissolved ions followed by ions-mediated protein activity disequilibrium, is the most frequent and effective [28,38,39]. $\mathrm{ZnO}$ NPs has high potential to generate ROS species in air or water (superoxide anion $\left[\mathrm{O}_{2} \bullet-\right]$, hydrogen peroxide $\left[\mathrm{H}_{2} \mathrm{O}_{2}\right]$, hydroxyl radical $\left[{ }^{\bullet} \mathrm{OH}\right]$ and singlet oxygen $\left[{ }^{1} \mathrm{O}_{2}\right]$ ), under UV illumination, ambient
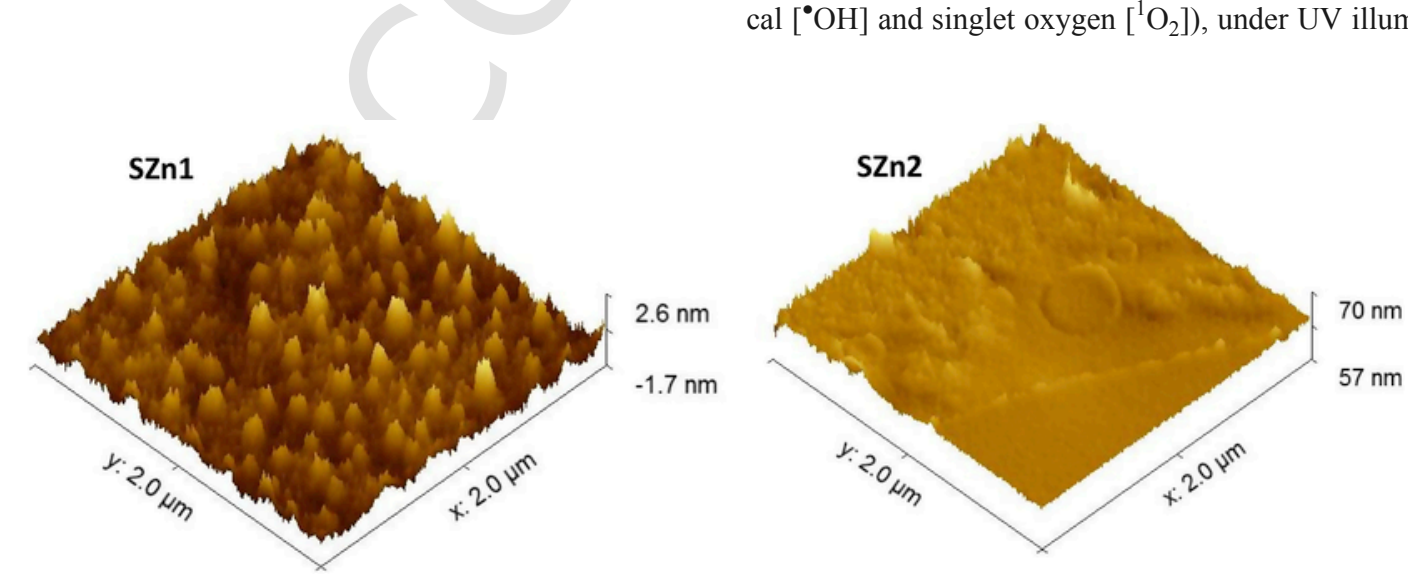

Fig. 6. AFM images of one-layered (SZn1) and two-layered (SZn2) ZnO/Cs/PMMA thin films. 

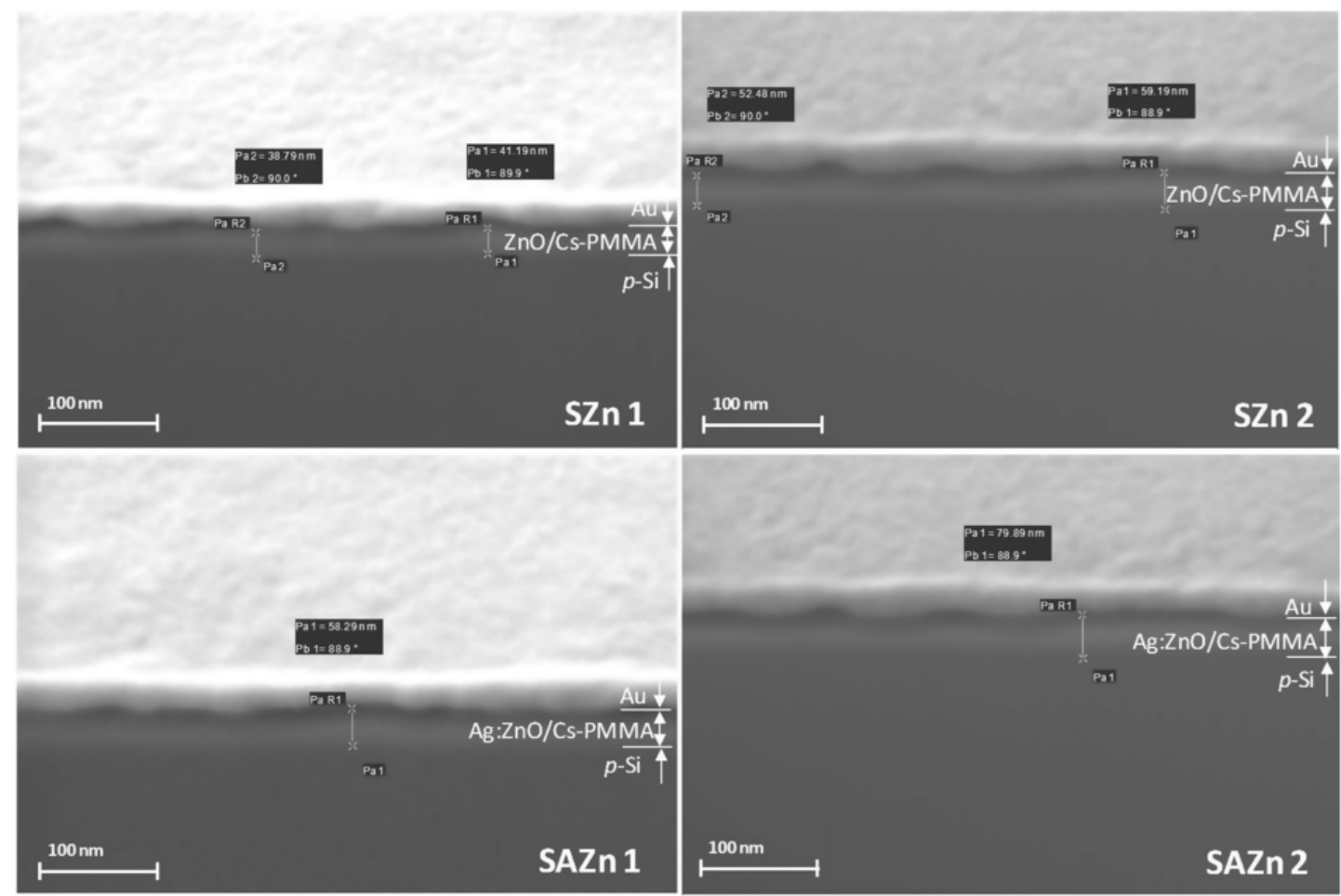

Fig. 7. Cross sectional SEM images of $\mathrm{ZnO} / \mathrm{Cs} / \mathrm{PMMA}$ and $\mathrm{Ag}: \mathrm{ZnO} / \mathrm{Cs} / \mathrm{PMMA}$ thin films with one (SZn1, SAZn1) and two (SZn2, SAZn2) layers.

light, or even in the dark [39]. Due to its direct band-gap value, $\mathrm{ZnO}$ is normally excited by UV light. Under UV irradiation, the electrons $\left(\mathrm{e}^{-}\right)$from the valence band reach the conduction band, leaving holes $\left(\mathrm{h}^{+}\right)$in the valence band. Usually electrons and holes recombine quickly but in the case of nanoparticles they move up to the nanoparticle surface, where they react with the adsorbed species (water and oxygen molecules) generating firstly hydroxyl radicals or $\mathrm{O}_{2}{ }^{-2}$ and finally hydrogen peroxide ROS. ZnO NPs possess higher photocatalytic efficiency, are more biocompatible than $\mathrm{TiO}_{2} \mathrm{NPs}$ and can highly absorb UV light with an increased conductivity and ROS generation that significantly activate the interaction with bacteria and photocatalytic activity. In the case of $\mathrm{ZnO}$ nanoparticles, electrons can also jump to the conduction band without UV irradiation, which explains its ability to generate ROS species also under visible light [39]. In the case of silver, the $\operatorname{ROS}\left(\mathrm{O}_{2}^{-}, \mathrm{O}_{2}{ }^{-2}\right)$ can be generated under ambient condition, by incompletely reducing of $\mathrm{O}_{2}$ molecules from air chemically adsorbed on the 111 face of Ag NPs, simultaneous with the formation of $\mathrm{Ag}^{+}$ions by oxidizing the surface $\mathrm{Ag}$ atom [35]. Ag-doped $\mathrm{ZnO}$ NPs have been found to be heteronanostructures consisting of small metallic silver nanoparticles (quantum dots) located on the surface of ZnO NPs [40,41]. They are considered to be one of the most important antimicrobial agents and photocatalysts against pathogenic microorganisms. In Ag: $\mathrm{ZnO}$ nanoparticles, the concentration of oxygen vacancy increases because the Ag doping in $\mathrm{ZnO}$ nanocrystals is associated with induction of oxygen vacancies. The presence of metallic Ag nanoparticles and oxygen vacancies on the surface of $\mathrm{ZnO}$ NPs promotes the separation of generated electron-hole pairs and thus enhances the catalytic and antimicrobial activity [41]. In this interaction, the metallic Ag atoms accept electrons from the conduction band of $\mathrm{ZnO}$, thus preventing the electron-hole recombination and consequently generating an increase in (photo)electrical conductivity and ROS generation. An increased ROS concentration turns into enhanced (photo)catalytic and antimi- crobial activity. Any factor that will promote the separation of generated electron-hole pairs will increase the electrical conductivity and enhance the photocatalytic and antimicrobial activity of the nanoparticles.

To our knowledge, so far just a few studies that combine the use of PMMA, $\mathrm{ZnO}$ and $\mathrm{Cs}$ in the production of functional thin films have been reported. Petchthanasombat et al. prepared hybrid core-shell PMMA/Cs-ZnO nanoparticles obtained by $\mathrm{ZnO}$ dispersion in poly(methyl methacrylate)-chitosan matrix by an emulsifier-free emulsion polymerization method and investigated their physicochemical properties and electrochemical behavior for developing biosensors [17]. In a previous paper we report the preparation of a hybrid material based on acrylic copolymer modified with $\mathrm{ZnO} /$ chitosan and $\mathrm{Ag}: \mathrm{ZnO} /$ chitosan composite nanoparticles for applications in prosthodontics [42]. According to our knowledge, no dielectric thin films with this composition (PMMA, $\mathrm{Cs}, \mathrm{ZnO}$ and $\mathrm{Ag}: \mathrm{ZnO}$ ) have been reported.

In this work, we present new hybrid $\mathrm{ZnO} / \mathrm{Cs} / \mathrm{PMMA}$ and $\mathrm{Ag}: \mathrm{ZnO} /$ Cs/PMMA thin films based on $\mathrm{ZnO}$ and $\mathrm{Ag}: \mathrm{ZnO}$ nanoparticles dispersed in chitosan and incorporated poly(methyl methacrylate) matrix, deposed on glass and $p$-Si substrates by a modified sol-gel method. In the investigated hybrid films we combined for the first time antimicrobial $(\mathrm{Ag}, \mathrm{ZnO})$ and biocompatible $(\mathrm{Cs})$ components with different electrical properties, to create new functionalities to the PMMA - based dielectric films for new applications. The effect of the added components (metal and semiconductor) on the optical and dielectric properties of the resulting hybrid films, as well as the new acquired antimicrobial properties have been investigated, in correlation with their structure and morphology. We consider this system to be an alternate dielectric gate material with the required dielectric properties and adherence to either rigid or flexible substrates at low processing temperature. (Ag) $\mathrm{ZnO} / \mathrm{Cs} / \mathrm{PMMA}$ thin films to be used in border applications such as bioelectronics and drug-delivery systems. 

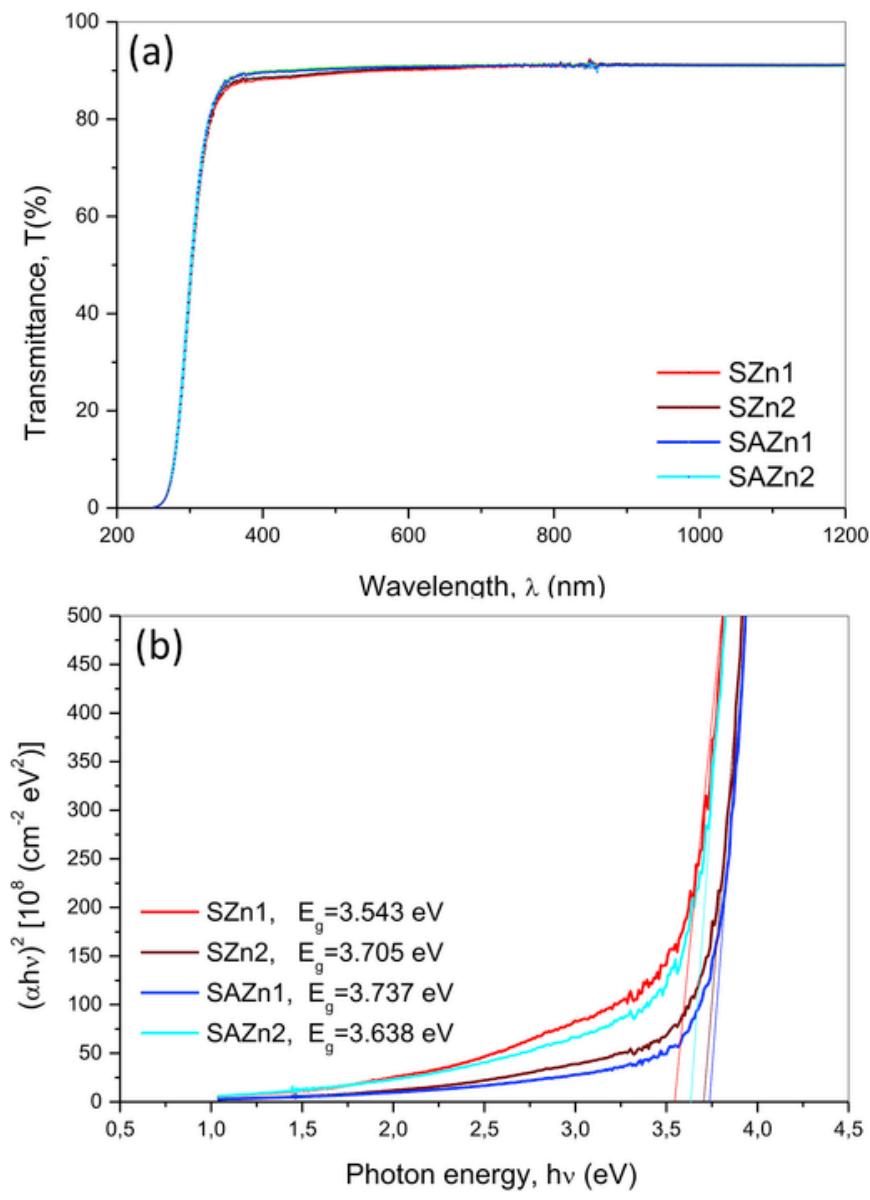

Fig. 8. Transmittance spectra (a) and band gap (b) of $\mathrm{ZnO} / \mathrm{Cs} / \mathrm{PMMA}$ and $\mathrm{Ag}: \mathrm{ZnO} / \mathrm{Cs} /$ PMMA thin films with one (SZn1, SAZn1) and two (SZn2, SAZn2) layers.

\section{Experimental procedures}

\subsection{Materials and samples preparation}

Zinc acetate dehydrate and chitosan with medium-molecular-weight (190-310 kDa) and 75-85\% degree of deacetylation (DD) purchased from Sigma-Aldrich Chemical Co, glacial acetic acid pur-

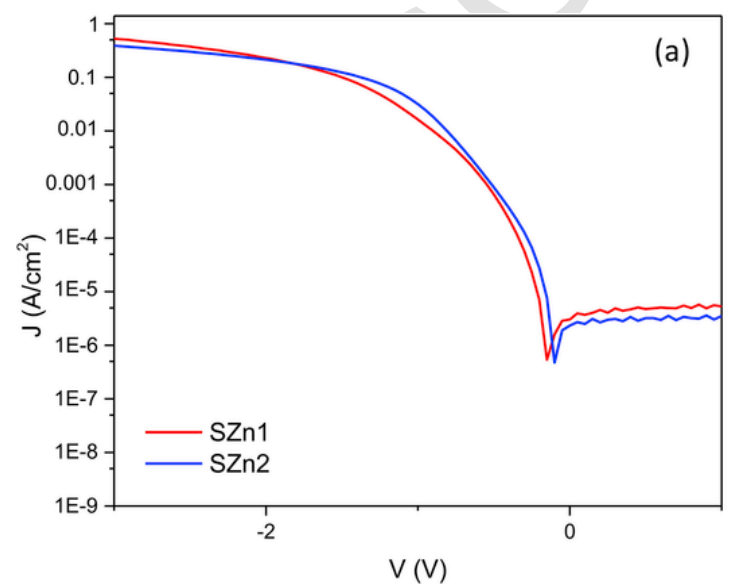

chased from Beker, silver nitrate $\left(\mathrm{AgNO}_{3}\right)$ purchased from Merck and methyl methacrylate (MMA) $495 \mathrm{kw}$ purchased from MICRO CHEM have been used as raw materials.

First, $\mathrm{ZnO}$ nanoparticles ( $\mathrm{ZnO} \mathrm{NPs}$ ) and $\mathrm{Ag}$ doped $\mathrm{ZnO}$ nanoparticles (Ag:ZnO NPs) were obtained using a method similar to Spanhel method [43]. The synthesis of $\mathrm{ZnO}$ and $\mathrm{Ag}: \mathrm{ZnO}$ NPs, realized by hydrolysis of zinc acetate $(0.035 \mathrm{M})$ or zinc acetate with silver nitrate (atomic ratios of 85:15) in isopropanol in the presence of lithium hydroxide $(\mathrm{LiOH})$, is presented in detail elsewhere [20]. The amount of silver doping was chosen on the basis of previous results because it led to lower size composite $\mathrm{Ag}: \mathrm{ZnO}$ nanoparticles [20], their best dispersion in chitosan and best antimicrobial properties [28]. Chitosan solution $(2 \%)$ was prepared by dissolving $0.2 \mathrm{~g}$ chitosan in $10 \mathrm{~mL} 2 \%(\mathrm{v} /$ v) acetic acid solution. The viscous chitosan solution was stirred for $18 \mathrm{~h}$ at room temperature before using. $\mathrm{ZnO} / \mathrm{Cs}$ and $\mathrm{Ag}: \mathrm{ZnO} / \mathrm{Cs} \mathrm{NPs}$ were obtained by incorporation of $\mathrm{ZnO}$ and $\mathrm{Ag}: \mathrm{ZnO}$ NPs into the before prepared chitosan solution at an equivalent molar ratio of $2: 1$. The hybrid precursor solutions used for the films deposition were obtained by incorporation of $\mathrm{ZnO} / \mathrm{Cs} / \mathrm{MMA} \mathrm{NPs}$ (Sol 1) and $\mathrm{Ag}: \mathrm{ZnO} / \mathrm{Cs} / \mathrm{MMA}$ NPs (Sol 2) into methyl methacrylate (MMA) solution and stirred for 15 min at room temperature. The equivalent molar ratio of $\mathrm{ZnO} / \mathrm{Cs} /$ MMA and $\mathrm{Ag}: \mathrm{ZnO} / \mathrm{Cs} / \mathrm{MMA}$ was 2:1:3.

The $p$-Si substrates were cleaned with acetone and isopropanol for $30 \mathrm{~min}$ in ultrasonic bath at $60^{\circ} \mathrm{C}$, immersed in $\mathrm{HF}$ to remove the native $\mathrm{SiO}_{2}$ from the surface, dried under $\mathrm{N}_{2}$, followed by a $15 \mathrm{~min} \mathrm{UV/}$ Ozone surface activation using a PSD-UV Novascan System, prior to use for film deposition. The $\mathrm{ZnO} / \mathrm{Cs} / \mathrm{PMMA}$ and $\mathrm{Ag}: \mathrm{ZnO} / \mathrm{Cs} / \mathrm{PMMA}$ thin films were deposited by spin-coating the precursor solution for $20 \mathrm{~s}$ at $3000 \mathrm{rpm}$ using Laurell Technologies equipment, in one layer (SZn1 and SAZn1) and two-layers (SZn2 and SAZn2). Each layer was annealed in air at $160^{\circ} \mathrm{C}$ for $5 \mathrm{~min}$, followed by $30 \mathrm{~min} \mathrm{UV} /$ Ozone exposure [44].

The capacitors were produced onto $p$-Si substrates in a Metal-Insulator-Semiconductor (MIS) structure consisting of $\mathrm{ZnO} / \mathrm{Cs} / \mathrm{PMMA}$ and $\mathrm{Ag}: \mathrm{ZnO} / \mathrm{Cs} / \mathrm{PMMA}$ thin film with thickness of $\sim 40$ and $\sim 60 \mathrm{~nm}$ for samples SZn1 and SZn2 and $\sim 60$ and $\sim 80 \mathrm{~nm}$ for samples SAZn1 and SAZn2, respectively, arranged between two metallic thin films of aluminum (bottom and top electrode) (Fig. 1). Aluminum electrodes ( $80 \mathrm{~nm}$ thick) were vacuum-deposited by thermal evaporation (BOC Edwards Auto 306-EXC 120) via shadow mask.

\subsection{Samples characterization}

The Fourier transform infrared (FTIR) spectra of chitosan solution, commercially MMA, $\mathrm{ZnO}$ and $\mathrm{Ag}: \mathrm{ZnO}$ nanoparticles, prepared

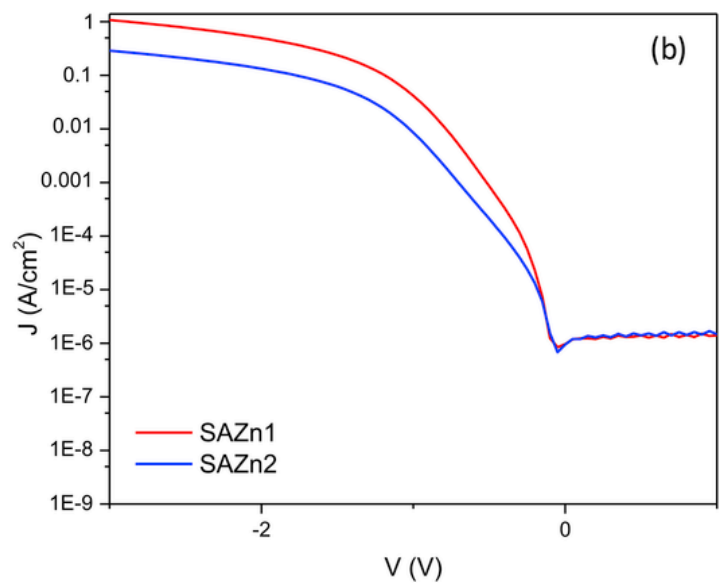

Fig. 9. I -V curves (1 MHz) of ZnO/Cs/PMMA (a) and Ag:ZnO/Cs/PMMA (b) thin films with one (SZn1, SAZn1) and two (SZn2, SAZn2) layers. 

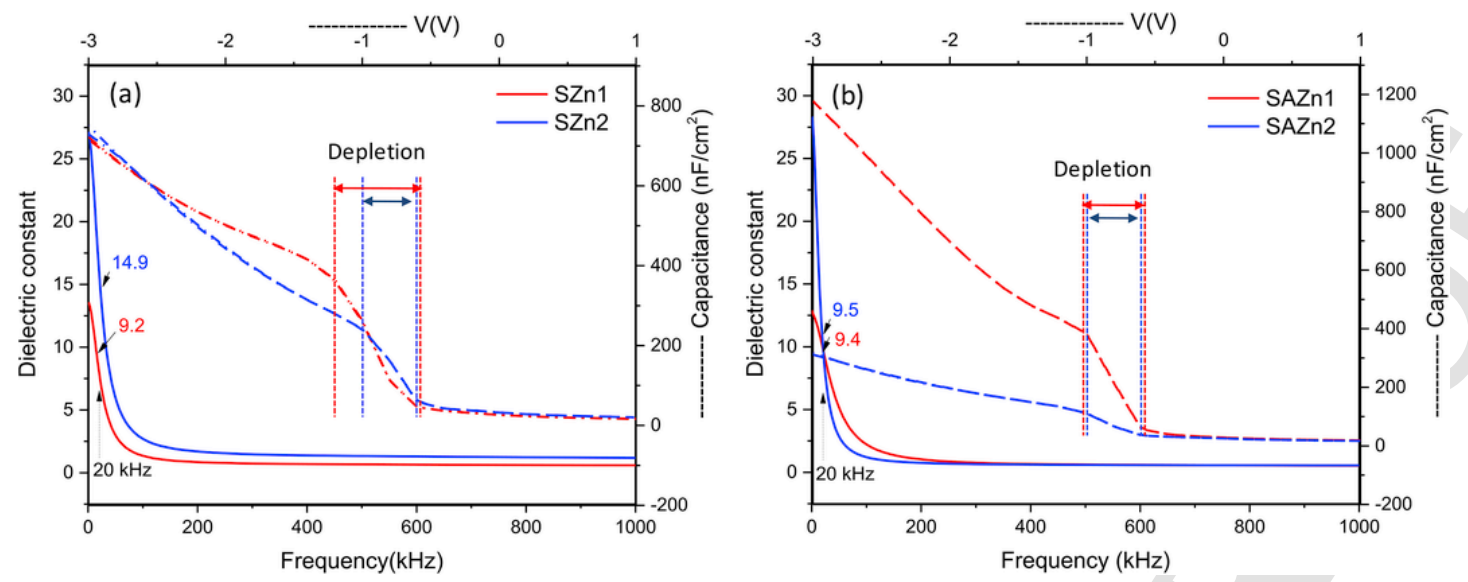

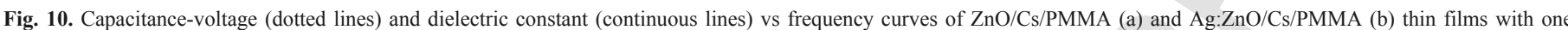
(SZn1, SAZn1) and two (SZn2, SAZn2) layers.

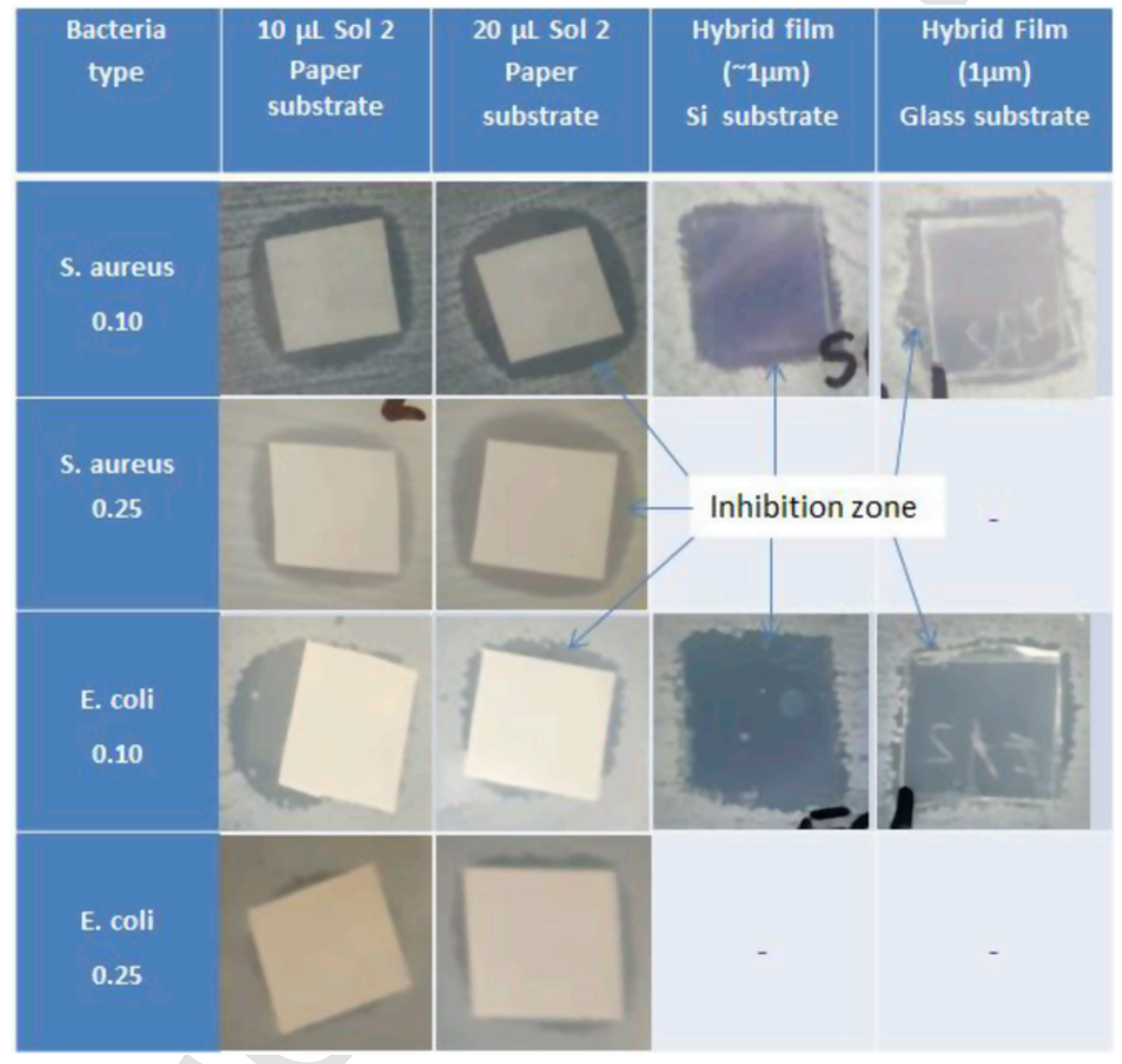

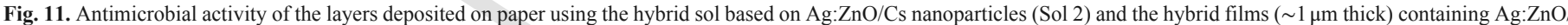

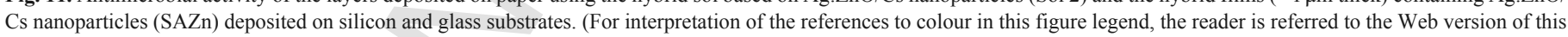
article.)

hybrid solution based on $\mathrm{ZnO} / \mathrm{Cs} / \mathrm{MMA}$ (Sol 1) and $\mathrm{Ag}: \mathrm{ZnO} / \mathrm{Cs} /$ MMA (Sol 2) and hybrid thin films with two layers (SZn2 and SAZn2) were recorded in the range between 4000 and $450 \mathrm{~cm}^{-1}$ using NICOLET 6700 Advanced FTIR spectrometer from Termo Scientific and attenuated total reflectance (ATR) method on a ZnSe crystal.

The morphology of the $\mathrm{ZnO}$ and $\mathrm{Ag}: \mathrm{ZnO}$ nanoparticles was performed by scanning electron microscopy using a Carl Zeiss AURIGA CrossBeam (FIB-SEM) workstation coupled with energy dispersive
X-ray spectroscopy (EDS) for analysis of elemental composition and mapping. Sample nanoparticles examined at SEM were obtained by direct evaporation on the carbon band of a drop of an alcoholic dispersion therefore. Cross-section SEM images of the films were obtained using a ZEISS Auriga cross beam instrument in focus ion beam (FIB) mode. Ga ions were used for the physical sputtering (milling) of the film and the images were recorded using the in-column SEM set up functioning at $2 \mathrm{KV}$ with a working distance of 
$5 \mathrm{~mm}$. A thin protection layer of $\mathrm{Au}$ was deposited onto the film surface prior to the milling and this layer appears as a white region on the top of the films. The surface topography of the obtained hybrid thin films was investigated through atomic force microscopy (AFM) using Asylum MFP3D equipment. The top view images were analyzed by the Gwyddion software, in order to obtain the surface roughness of synthesized samples.

The optical response of the samples was measured with a double beam ultra-violet, visible and near infra-red (UV-Vis-NIR) spectrophotometer from PerkinElmer (Lambda 950) equipped with an integrating sphere, in the wavelength range of 300-1200 nm.

Differential scanning calorimetry (DSC) and thermogravimetric analysis (TGA) were carried out using the simultaneous thermal analyzer TGA-DSC_-STA 449 F3 Jupiter from Netzsch. Approximately $25 \mathrm{mg}$ of sample was loaded into a closed aluminum crucible and heated from room temperature to $550^{\circ} \mathrm{C}$ with a heating rate of $10^{\circ} \mathrm{C}$ $\min ^{-1}$, in synthetic air.

The dielectric properties of the $\mathrm{ZnO} / \mathrm{Cs} / \mathrm{PMMA}$ and $\mathrm{Ag}: \mathrm{ZnO} / \mathrm{Cs} /$ PMMA capacitors were performed measuring both the current-voltage, the capacitance-voltage and capacitance-frequency characteristics of the devices in the range of $1 \mathrm{kHz}$ to $1 \mathrm{MHz}$, using the semiconductor device analyzer KEYSIGHT B1500A.

The dielectric constant values $\left(k_{i}\right)$ of the hybrid thin films were determined using Eq. (1) for a parallel plate capacitor, The dielectric constant $\left(k_{i}\right)$ values of the hybrid films were determined from the capacitance-frequency measurements, using Eq. (1) for a parallel plate capacitor:

$$
k_{i}=\frac{C}{\varepsilon_{0}} \cdot \frac{t}{A}
$$

where $\varepsilon_{0}$ is the permittivity of free space, $t$ is the film thickness, $A$ is the area of the capacitor and $C$ is the measured capacitance [45].

The antimicrobial activity of 10 and $20 \mu \mathrm{L}$ hybrid sols (Sol 1 and Sol 2) deposited on sterile $7 \mathrm{~mm}$ side paper sheets was tested against Gram-negative bacteria Escherichia coli (reference strains $E$. coli ATCC 25922) and Gram-positive bacteria Staphylococcus aureus (reference strains $S$. aureus ATCC 25923) of 0.1 and $0.25 \mathrm{McFar}-$ land concentration, on the Mueller-Hinton agar medium. The hybrid sols deposited on the paper were dried at $120^{\circ} \mathrm{C}$ for $2 \mathrm{~h}$. After cooling to room temperature, the samples were gently pressed against the medium plate to have good contact with the bacteria-inoculated agar and then were kept in incubator at constant temperature at $37^{\circ} \mathrm{C} \pm 1^{\circ} \mathrm{C}$ for $24 \mathrm{~h}$, before the inhibition zones were observed. A similar procedure has also been used to measure the antimicrobial activity of $\mathrm{Ag}: \mathrm{ZnO} / \mathrm{Cs} / \mathrm{PMMA}$ hybrid films (about $1 \mu \mathrm{m}$ thick) deposited on silicon and glass substrates.

\section{Results and discussion}

\subsection{Structure and morphology}

The SEM images of $\mathrm{ZnO}$ and $\mathrm{Ag}: \mathrm{ZnO}$ nanoparticles (Fig. 2), used for the preparation of hybrid complex thin films, show aggregates formed from plate like nanoparticles with diameters ranging from 100 to $250 \mathrm{~nm}$ for $\mathrm{ZnO}$ and between 60 and $150 \mathrm{~nm}$ for $\mathrm{Ag}: \mathrm{ZnO}$. It can be noticed that in the case of Ag-doped nanoparticles both the size of the nanoparticles and their agglomerates decrease. In the used synthesis method, the $\mathrm{Ag}^{+}$ions existing in the solution directly precipitate as metallic nanoparticles on the surface of the oxide nanoparticles $(\mathrm{ZnO})$ being formed, thus limiting their growth [40]. In a previous paper we showed that the size of $\mathrm{ZnO}$ and $\mathrm{Ag}: \mathrm{ZnO}$ nanoparticles synthesized by the same method, estimated from high resolution transmission electron micrographs (HR-TEM), ranges between 10-20 and $8-15 \mathrm{~nm}$, respectively [42]. When comparing the values of the SEM imagines to the latter ones, one can conclude that the former ones (Fig. 2) are secondary particles consisting of agglomerates of primary synthetized nanoparticles.

The elemental composition of nanoparticles used for the preparation of hybrid thin films analyzed by EDX spectra and elemental mapping are shown in Fig. 3.

The FTIR spectra of the precursors used for films preparation, meaning chitosan solution ( $2 \mathrm{wt} \%$ ), MMA solution, $\mathrm{ZnO}$ and $\mathrm{Ag}: \mathrm{ZnO}$ NPs, as well as $\mathrm{ZnO} / \mathrm{Cs} / \mathrm{PMMA}$ (Sol 1) and $\mathrm{Ag}: \mathrm{ZnO} / \mathrm{Cs} / \mathrm{PMMA}$ (Sol 2) hybrid sols and the resulted hybrid films with two layers (SZn2 and SAZn2) are shown in Fig. 4. The spectrum of MMA shows three characteristic peaks at 1158,1442 and $1723 \mathrm{~cm}^{-1}$ assigned to $\mathrm{O}-\mathrm{CH}_{3}$ stretching, $\mathrm{CH}_{3}$ stretching and $\mathrm{C}=\mathrm{O}$ stretching, respectively [46]. The FTIR spectra of chitosan solution 2\% show the characteristic broad band between 3200 and $3600 \mathrm{~cm}^{-1}$ corresponding to the stretching vibrations of $\mathrm{O}-\mathrm{H}(-\mathrm{OH})$ and $\mathrm{N}-\mathrm{H}\left(-\mathrm{NH}_{2}\right)$ bonds [47]. The peaks at 1634 and $1390 \mathrm{~cm}^{-1}$, assigned to amide I and amide II bands of chitosan, confirmed that the polymer was only a partially deacetylated product $(75-85 \%)$. Especially, the amide I band, present in the spectrum due to $\mathrm{C}=\mathrm{O}$ stretching, indicated the presence of $\mathrm{CH}_{3}-\mathrm{C}=\mathrm{O}$ groups in a chitosan molecule [48]. Apart from the above-mentioned amide bands, the spectrum of chitosan displayed a set of characteristic saccharide bands situated in the range of $1100-900 \mathrm{~cm}^{-1}$ [49]. The spectrum of $\mathrm{ZnO}$ and $\mathrm{Ag}: \mathrm{ZnO}$ nanoparticles shows a broad peak between 3200 and $3600 \mathrm{~cm}^{-1}$ associated to the vibration of $\mathrm{O}-\mathrm{H}$ bond of the adsorbed and chemosorbed water and a band below $500 \mathrm{~cm}^{-1}$ related to the $\mathrm{Zn}-\mathrm{O}$ stretching vibration [50]. The peaks located at 1575, 1414, 1020 and $859 \mathrm{~cm}^{-1}$ are assigned to the stretches of carbonate groups of the residual hydrozincite phase existing in zinc oxide nanoparticles prepared from solution [51]. The spectra of $\mathrm{ZnO} / \mathrm{Cs} / \mathrm{MMA}$ highlights increased intensity peaks, especially at $1044 \mathrm{~cm}^{-1}$ which is shifted towards higher energy value, compared to the above-mentioned shift of the stretching vibration band of carbonate groups of $\mathrm{ZnO}$ nanoparticles sample $\left(1020 \mathrm{~cm}^{-1}\right)$. The peak assigned to the amide I band of chitosan $\left(1634 \mathrm{~cm}^{-1}\right)$ is also shifted to the higher energy value for $\mathrm{ZnO}$ / $\mathrm{Cs} / \mathrm{MMA}$ solution $\left(1652 \mathrm{~cm}^{-1}\right)$. All these modifications can provide an important evidence of chemical interaction between the components [42]. Also, the presence of the characteristic peaks clearly proves that MMA has been successfully grafted onto the chitosan surface [52].

The FTIR spectra highlight the chemical structure of the post-deposition treated films (SZn2 and SAZn2 in Fig. 4a). A new molecular structure is revealed for these hybrid films, different from that of raw materials and of the hybrid sols used for films deposition (Sol 1 and Sol 2), by the presence of two broad bands in the $600-1200 \mathrm{~cm}^{-1}$ domain with maxima at about 900 and $1080 \mathrm{~cm}^{-1}$ (Fig. 4a). The presence of the broad bands, which suggest the formation of quasi amorphous complex nanocomposites, can be attributed to the overlapping of characteristic vibrations of saccharide bands of chitosan situated in the range of $1100-900 \mathrm{~cm}^{-1}$ and the characteristic $\mathrm{C}-\mathrm{O}-\mathrm{C}$ stretching vibrations of acrylic matrix (PMMA), modified by chemical and intermolecular reciprocal interactions in the presence of $\mathrm{ZnO}$ and $\mathrm{Ag}: \mathrm{ZnO}$ nanoparticles. The details of FTIR spectra highlight the presence of residual $\mathrm{O}-\mathrm{H}$ groups (Fig. 4b) and suggest the presence of carbonate groups of zyncite phase [51] (Fig. 4c) in the post-deposed treated films.

The results of the thermal analysis of $\mathrm{ZnO} / \mathrm{Cs} / \mathrm{MMA}$ and $\mathrm{Ag}: \mathrm{ZnO} /$ Cs/MMA solutions performed by TG-DSC measurements are shown in Fig. 5. The thermogram of $\mathrm{ZnO} / \mathrm{Cs} / \mathrm{MMA}$ (Sol 1) and $\mathrm{Ag}: \mathrm{ZnO} / \mathrm{Cs} /$ MMA (Sol 2) show a weight loss of about $81 \%$ and $92 \%$, respectively, which may be attributed to the loss of solvent as well as chemically water and compounds resulting from reactions between the pre- 
cursors or their thermal decomposition. The DSC curves indicate two major processes, an endothermic process below $100^{\circ} \mathrm{C}$ and an exothermic one between 400 and $500^{\circ} \mathrm{C}$. The first process, with peaks at 37 and $47^{\circ} \mathrm{C}$ is mainly related with solvent evaporation and the second one with the exothermic decomposition of the acrylic matrix (PMMA) grafted with chitosan which covers the $\mathrm{ZnO}$ and $\mathrm{Ag}: \mathrm{ZnO}$ nanoparticles [42]; the shift to higher temperature of thermal decomposition of the hybrid matrix, from 436 to $454^{\circ} \mathrm{C}$, confirm stronger interactions into the $(\mathrm{Ag}) \mathrm{ZnO} / \mathrm{Cs} / \mathrm{MMA}$ hybrid material.

Fig. 6 shows the AFM surface morphology, in an area of $2 \times 2 \mu \mathrm{m}^{2}$, of one-layer (SZn1) and two-layered (SZn2) $\mathrm{ZnO} / \mathrm{Cs} / \mathrm{PMMA}$ thin films deposed onto $p$-Si substrate. The root mean square (RMS) roughness, evaluated with the Gwyddion software in $2 \times 2 \mu \mathrm{m}^{2}$ area, is 1.84 and $2.79 \mathrm{~nm}$ for $\mathrm{SZn} 1$ and $\mathrm{SZn} 2$, respectively, which means a low surface roughness of the obtained hybrid films. An increase of the roughness with increasing from one to two the number of layers is observed. There are not evidences of separate phase precipitation at the micrometric scale. Thus, the AFM phase images confirm the formation of homogeneous hybrid organic-inorganic thin films.

The average thickness of the investigated thin films with one and two layers, measured from cross sectional SEM images, was 40 and $60 \mathrm{~nm}$ for $\mathrm{ZnO} / \mathrm{Cs} / \mathrm{PMMA}$ and 60 and $80 \mathrm{~nm}$ for $\mathrm{Ag}: \mathrm{ZnO} / \mathrm{Cs} / \mathrm{PMMA}$, respectively (Fig. 7).

From Fig. 8a one can be observed that the transmittance spectra of all the thin films is about $90 \%$ in the visible range, indicating very good potential applications in transparent electronics. The values of the optical band gap energy $\left(\mathrm{E}_{\mathrm{g}}\right)$ of the investigated thin films, extracted by plotting $(\alpha h \nu)^{2}$ against the photoenergy $h \nu$ and extrapolating to the energy axis, are shown in Fig. $8 \mathrm{~b}$.

Very generally presented, the optical $\mathrm{E}_{\mathrm{g}}$ values of the investigated films ranges between 3.543 and $3.737 \mathrm{eV}$. In the case of nanoparticles-based thin films, the first correlation for variation of the $E_{g}$ value is related to the nanoparticles size. It is known that, according to quantum size effect, smaller nanoparticle size lead to higher optical $\mathrm{E}_{\mathrm{g}}$ values [53]. Taking into account the size of the crystalline nanoparticles, only the one-layer investigated films (SZn1 and SAZn1) show an expected behavior, the $E_{g}$ value increasing from $3.543 \mathrm{eV}$ in the case of the film with larger $\mathrm{ZnO}$ nanoparticle (SZn1) to $3.737 \mathrm{eV}$ for the film containing smaller Ag: $\mathrm{ZnO}$ nanoparticles (SAZn1). In the case of two-layers films, this simple correlation is no longer appropriate. The $\mathrm{E}_{\mathrm{g}}$ value decreases from $3.705 \mathrm{eV}$ for the film with larger $\mathrm{ZnO}$ NPs (SZn2) to $3.638 \mathrm{eV}$ for the film with smaller $\mathrm{Ag}: \mathrm{ZnO}$ nanoparticles $(\mathrm{SAZn} 2)$. The $\mathrm{E}_{\mathrm{g}}$ value of $\mathrm{SAZn} 2$ film with the highest thickness $(80 \mathrm{~nm})$ is lower than the $E_{g}$ values of the film with $\mathrm{ZnO}$ nanoparticles (SZn2) and of the film with $\mathrm{Ag}: \mathrm{ZnO}$ nanoparticles (SAZn1), both films having the same thickness of $60 \mathrm{~nm}$. This variation indicates that with the increase in film thickness, the particle size factor is no longer dominant. In the case of such complex films, in addition to the nanoparticle size, the concentration of crystalline nanoparticles and (macro)molecules along the optical radiation way through the film (film thickness), as well as the electrical behavior (conductive, semiconductor or dielectric) of the components must be taken into consideration for the optical $\mathrm{E}_{\mathrm{g}}$ values. The hybrid films presented in this study contain metal conductive compound $(\mathrm{Ag})$, semiconductor compound $(\mathrm{ZnO})$ and dielectric polymers (Cs and PMMA). According to literature data, the optical band gap values for thin films based on the individual components included in our new hybrid films are $3.26 \mathrm{eV}$ for $\mathrm{ZnO}$ [54], 3.27-3.28 eV for $\mathrm{Ag}: \mathrm{ZnO}$ [55], $4.055 \mathrm{eV}$ for chitosan with medium molecular weight [56] and 3.6-3.9 eV for PMMA [57]. In the case of the SAZn2 film with the highest thickness $(80 \mathrm{~nm})$ and implicitly with the highest concentration of $\mathrm{Ag}$ on the radiation way crossing the film (film thickness), the effect of enhanced conductivity of $\mathrm{Ag}: \mathrm{ZnO}$
NPs, explained before (Section 1. Introduction), in decreasing the optical $E_{g}$ value is dominant. $E_{g}$ values of all the obtained hybrid films are close to that of polymeric PMMA films and can recommend their investigation for potential dielectric gate application in thin films transistors.

Fig. 9 shows the $\mathrm{I}-\mathrm{V}$ characteristic curves of $\mathrm{ZnO} / \mathrm{Cs} / \mathrm{PMMA}$ and $\mathrm{Ag}: \mathrm{ZnO} / \mathrm{Cs} / \mathrm{PMMA}$ thin films for applied gate voltages from -3 to $+1 \mathrm{~V}$. In the inversion region $(0$ and $+1 \mathrm{~V})$, the leakage current density of one layer (SZn1) and two-layered (SZn2) films with $\mathrm{ZnO} /$ Cs nanoparticles is $5 \times 10^{-6}$ and $3 \times 10^{-6} \mathrm{~A} / \mathrm{cm}^{2}$ respectively, and slightly decreases for films containing $\mathrm{Ag}: \mathrm{ZnO}$ nanoparticles (SAZn1 and SAZn2) to about $1 \times 10^{-6} \mathrm{~A} / \mathrm{cm}^{2}$. The slight decrease of the leakage current in the case of the two-layers $\mathrm{ZnO}$ film (SZn2) compared to one-layer film (SZn1) is due to the decrease of the electric field with the increase in film thickness (Fig. 9a). For the films containing $\mathrm{Ag}: \mathrm{ZnO}$ composite nanoparticles (Fig. 9b), two phenomena are observed compared to the films with ZnO NPs (Fig. 9a): in the presence of $\mathrm{Ag}$, the leakage current does not decrease for the thicker film $(80 \mathrm{~nm})$ with two layers $(\mathrm{SAZn} 2)$ compared to the thinner film $(60 \mathrm{~nm})$ with one-layer $(\mathrm{SAZn} 1)$ and the leakage current value $\left(1 \times 10^{-6} \mathrm{~A} / \mathrm{cm}^{2}\right)$ is slightly lower than the corresponding values for one- and two-layered films without $\mathrm{Ag}$ (SZn1 and SZn2, respectively). This behavior can be explained by the fact that in the case of thicker film with Ag the decrease of the field value with the increase of film thickness is compensated by the increase in conductivity due to the increase of carrier number. At the same time, a decrease in current leakage in the case of $\mathrm{Ag}: \mathrm{ZnO}$-based films compared to $\mathrm{ZnO}$-based films can be explained by the braking of electrons displacement through the material layer (film thickness) following collision with larger $\mathrm{Ag}^{+}$ions/atoms, which causes a decrease of mobility and, implicitly, of conductivity.

In the accumulation region $(-3$ and $-1.5 \mathrm{~V})$, the current density is higher (Fig. 9) and need future experimental work to be improved for applications as dielectric thin films gate. These values, which are higher than the characteristic leakage current reported for PMMA $\left(10^{-8} \mathrm{~A} / \mathrm{cm}^{2}\right)$ [58], could be explained by the presence of residual $\mathrm{O}-\mathrm{H}$ groups $[59,60]$. Although after combined thermal $\left(160^{\circ} \mathrm{C}\right)$ and $\mathrm{UV}$ irradiation treatment the films show, through comparisons with precursors (Fig. 4a), a drastic decrease of O-H peaks (between 3000 and $3750 \mathrm{~cm}^{-1}$ ), the small peaks in FTIR spectra of thin films (Fig. 4b) indicate that the hydroxyl groups are still present in residual quantities. Further studies are taking into consideration to explain the electrical behavior with the effect of processing temperature to reduce the content of hydroxyl groups in the films.

The $\mathrm{C}-\mathrm{V}$ curves of the investigated thin films (Fig. 10) in MIS capacitor structure of $1 \mathrm{~mm}$ in diameter surface (Fig. 1), at $100 \mathrm{kHz}$ frequency, show accumulation, depletion and inversion regions [60]. The depletion region of the two-layered $\mathrm{ZnO} / \mathrm{Cs} / \mathrm{PMMA}(\mathrm{SZn} 2)$ film (Fig. 10a) and of the both one- and two-layered $\mathrm{Ag}: \mathrm{ZnO} / \mathrm{Cs} / \mathrm{PMMA}$ (SAZn1, SAZn2) films (Fig. 10b) is well defined between -1 and $-0.6 \mathrm{~V}$, while for the one-layered $\mathrm{ZnO} / \mathrm{Cs} / \mathrm{PMMA}$ film ( $\mathrm{SZn} 1$ ) it is larger and less precisely defined (Fig. 10a). The behavior of films with $\mathrm{ZnO}$ NPs (Fig. 10a) can be explained taking into consideration that for one layer the thickness of the film is small $(40 \mathrm{~nm})$, the dielectric constant is lower (9.2) and, as a result, the depletion starts at lower frequency $(\sim 440 \mathrm{kHz})$. For the two-layered film $(60 \mathrm{~nm})$, the depletion starts at higher frequencies $(\sim 500 \mathrm{kHz})$ due to the increase in the dielectric constant (14.9) as a result of the dominant dielectric behavior of the polymers components (PMMA and Cs) with the increase in film thickness. In the case of the films with Ag:ZnO NPs (Fig. 10b), the dominant effect (previously discussed at the variation of the optic bad gap value) of Ag in increasing the conductivity of the film results in a decrease in the dielectric constant when the film thickness increases, which compensates the effect of dielectric com- 
ponents in increasing the dielectric constant with the thickness increase, resulting in very close values, 9.4 and 9.5 for SAZn1 $(60 \mathrm{~nm})$ and SAZn2 $(80 \mathrm{~nm})$, respectively. As a result, the depletion area starts at very near frequency (around $500 \mathrm{kHz}$ ) for both films.

In the inversion region, between 0 and $+1 \mathrm{~V}$, the carrier polarity being inverted, the measured capacity refers to minimum capacity values (Fig. 10a-b). For the accumulation region at applied voltage between -3 and $-1 \mathrm{~V}$, where for a p-type MIS capacitor the total capacity is given by the dielectric capacity, the general observation is that the capacity of the films varies, being affected by the leakage current, differently for the films containing silver nanoparticles compared to silver-free films. If in the case of films with $\mathrm{ZnO} / \mathrm{Cs}$ nanoparticles the capacity started from approximately the same values regardless of the number of layers, for films with $\mathrm{Ag}: \mathrm{ZnO}$ nanoparticles the capacity at different applied voltage depends to a greater extent on the film thickness. Thus, at $-3 \mathrm{~V}$ the capacitance of the one-layered SAZn1 film is 3 times higher than that of the two-layered SAZn2 film, both these values (1200 and $400 \mathrm{nF} / \mathrm{cm}^{2}$, respectively, Fig. 10b) being very different from the corresponding values for films that do not contain $\mathrm{Ag}$ (SZn1 and SZn2) and which are very close to each other (720 and $750 \mathrm{nF} / \mathrm{cm}^{2}$, respectively, Fig. 10a). The two-layered SAZn2 film with $\mathrm{Ag}: \mathrm{ZnO} / \mathrm{Cs}$ nanoparticles shows the smallest variation of the capacitance with the applied voltage and better accumulation behavior at negative applied voltage between -3 and $-1 \mathrm{~V}$ (Fig. 10b) of all the investigated films. The present result shows promising dielectric behavior of the $80 \mathrm{~nm}$ thick $\mathrm{Ag}: \mathrm{ZnO} / \mathrm{Cs} / \mathrm{PMMA}$ film and further research will be developed to be improved.

Fig. 10 also shows frequency dependent values of dielectric constant, most probably due to ionic movement of some residues inside the investigated films. All the obtained values at $20 \mathrm{kHz}$ (Fig. 10a) are much higher than that reported (3.5) for pure PMMA thin films [58]. The number of layers (film thickness) affects more the dielectric constant value for silver-free films (14.9 and 9.2 for SZn2 and SZn1, respectively, Fig. 10a) than for silver-containing films (9.5 and 9.4 for SAZn2 and SAZn1, respectively, Fig. 10b), the last values being closed with that one reported (9.2) by MD Morales-Acosta et al. for PMMA- $\mathrm{SiO}_{2}$ organic-inorganic hybrid films [58]. The explanation of the large dielectric constant values in the investigated hybrid films must take into consideration the contributions of highly polarizable bonds such as $\mathrm{C}-\mathrm{O}-\mathrm{C}, \mathrm{C}=\mathrm{C}, \mathrm{C}=\mathrm{O}$ and $\mathrm{O}-\mathrm{H}$ bonds [59] present inside the samples. The capacitance values decrease sharply until $\sim 3$ and $\sim 7$, respectively at $50 \mathrm{kHz}$ and below 3 at $100 \mathrm{kHz}$ (Fig. 10a-b). This behavior can be explained by the fact that at a sufficiently high frequency the dipolar moment orientation is limited by strong bonds between components inside the investigated samples and the interface traps do not respond, therefore their contribution to the capacitance and the dielectric constant diminishes [60]. The dielectric behavior of the $(\mathrm{Ag}) \mathrm{ZnO} / \mathrm{Cs}-\mathrm{PMMA}$ films might be controlled by the presence of residual hydroxyl groups in the hybrid films [60], confirmed by the FTIR spectra (Fig. 4b). In addition, we aim to optimize the Ag doping for a range of slightly lower concentrations, for the optimization of electrical/dielectric properties (especially leakage of currents).

The antimicrobial activity of the hybrid sols and thin films mentioned earlier have been also investigated. Fig. 11 shows the results of the inhibition zone test in dark conditions for antibacterial activity of the hybrid sol containing Ag: $\mathrm{ZnO} / \mathrm{Cs}$ nanoparticles (Sol 2) impregnated in the paper disk and the corresponding thin films (SAZn2) deposited on silicon and glass substrates. All the samples, placed on the surfaces of the bacteria-inoculated agar medium, show distinct zones of inhibition (clear areas with no bacterial growth) around them, both for $E$. coli and $S$. aureus bacteria.

The diameter of area of killed bacteria under and around the samples varies with the volume of the hybrid sol which has been impregnated in the paper disc and varies according to the type and concen- tration of the bacteria, indicating a better activity (larger inhibition zone) for $S$. aureus. These qualitative antimicrobial tests showed smaller inhibition areas around the thin films deposited on silicon and glass than those around the dried sol-impregnated paper samples, which can be explained by lower amount of active hybrid compound in the case of thin films (under $1 \mu \mathrm{m}$ thickness) deposited on glass and silicon.

\section{Conclusions}

This paper reports on synthesis of new multifunctional transparent hybrid (Ag)ZnO/Cs/PMMA thin films with band gap energy values between 3.543 and $3.737 \mathrm{eV}$ in MIS structure, investigated for biocompatible electronic applications including dielectric gate in TFT device.

The hybrid thin films show low surface roughness, high optical transmittance in Vis-NIR of about $90 \%$ and dielectric constant between 9.2 and 9.5 at $20 \mathrm{kHz}$.

The presence of $\mathrm{Ag}$ in the composition slightly decreases the leakage current density from $5 \times 10^{-6}$ to $1 \times 10^{-6} \mathrm{~A} / \mathrm{cm}^{2}$ and improved the capacitance of films, indicating high potential applications of the hybrid films in transparent electronics.

The present results show promising dielectric behavior of $\mathrm{Ag}: \mathrm{ZnO} /$ Cs/PMMA hybrid films and further research will be developed to be improved leakage current value by reduction the hydroxyl and other residual groups.

The qualitative antimicrobial tests demonstrate antimicrobial activity against $E$. coli and $S$. aureus bacteria of $\mathrm{Ag}: \mathrm{ZnO} / \mathrm{Cs} / \mathrm{PMMA}$ hybrid sols and thin films deposited on silicon and glass substrates.

\section{Acknowledgment}

The authors thank Professor Nicolae Tigau from "Dunarea de Jos" University of Galati for calculation of the optical $\mathrm{E}_{\mathrm{g}}$ values and some useful discussions concerning their correlation with the electrical properties of the films.

\section{References}

[1] N.A.C. Lah, M.N.M. Zubir, M.A.-L. Samykano, Nanomaterial in electronics and electrical industries, in: C.M. Hussain (Ed.), Engineered Handbook of Nanomaterials for Industrial Applications, Elsevier Inc., USA, 2018, pp. 324-364.

[2] L. Zhang, W. Xiao, W. Wu, B. Liu, Research progress on flexible oxide-based thin film transistors, Appl. Sci. 9 (2019) 773.

[3] B. Wang, W. Huang, L. Chi, M. Al-Hashimi, T.J. Marks, A. Facchetti, High-k gate dielectrics for emerging flexible and stretchable electronics, Chem. Rev. 118 (2018) 5690-5754.

[4] M. Coll, J. Fontcuberta, M. Althammer, M. Bibes, H. Boschker, A. Calleja, G. Cheng, M. Cuoco, R. Dittmann, B. Dkhil, I. El Baggari, M. Fanciulli, I. Fina, E. Fortunato, C. Frontera, S. Fujita, V. Garcia, S.T.B. Goennenwein, C.-G. Granqvist, J. Grollier, R. Gross, A. Hagfeldt, G. Herranz, K. Hono, E. Houwman, M. Huijben, A. Kalaboukhov, D.J. Keeble, G. Koster, L.F. Kourkoutis, J. Levy, M. Lira-Cantu, J.L. MacManus-Driscoll, Jochen Mannhart, R. Martins, S. Menzel, T. Mikolajick, M. Napari, M.D. Nguyen, G. Niklasson, C. Paillard, S. Panigrahi, G. Rijnders, F. Sanchez, P. Sanchis, S. Sanna, D.G. Schlom, U. Schroeder, K.M. Shen, A. Siemon, M. Spreitzer, H. Sukegawa, R. Tamayo, J. van den Brink, N. Pryds, F. Miletto Granozio, Towards oxide electronics: a roadmap, Appl. Surf. Sci. 482 (2019) 1-93.

[5] R.L. Hoffman, ZnO-channel thin-film transistors: channel mobility, J. Appl. Phys. 95 (2004) 5813-5819.

[6] S. Li, L. Feng, J. Zhao, X. Guo, Q. Zhang, Low temperature cross-linked, high performance polymer gate dielectrics for solution-processed organic field-effect transistors, Polym. Chem. 6 (2015) 5884-5890.

[7] W. Tang, J. Li, J. Zhao, W. Zhang, F. Yan, X. Guo, High-performance solution processed low-voltage polymer thin-film transistors with low-k/high-k bilayer gate dielectric, IEEE Electron. Device Lett. 36 (2015) 950-952.

[8] K. Haase, M. Hambsch, C. Teixeira da Rocha, J. Zessin, S.C.B. Mannsfeld, Advances in solution processing of organic materials for devices, in: O. Ostroverkhova (Ed.), Handbook of Organic Materials for Electronic and Photonic Devices, Woodhead Publishing, USA, 2019, pp. 551-577. 
[9] T. Kitto, C. Bodart-Le Guen, N. Rossetti, F. Cicoira, Processing and patterning of conducting polymers for flexible, stretchable, and biomedical electronics, in: O. Ostroverkhova (Ed.), Handbook of Organic Materials for Electronic and Photonic Devices, Woodhead Publishing, USA, 2019, pp. 818-841.

[10] T. Someya, Z. Bao, G.G. Malliaras, The rise of plastic bioelectronics, Nature 540 (2016) 379-385.

[11] S. Iqbal, S. Ahmad, Recent development in hybrid conducting polymers: synthesis, applications and future prospects, J. Ind. Eng. Chem. 60 (2018) 53-84.

[12] J. Oliveira, V. Correia, H. Castro, P. Martins, S. Lanceros-Mendez, Polymer-based smart materials by printing technologies: improving application and integration, Addit. Manuf. 21 (2018) 269-283.

[13] M.G. Syamala Rao, M.A. Pacheco-Zuñiga, L.A. Garcia-Cerda, G. Gutiérrez-Heredia, J.A. Torres Ochoa, M.A. Quevedo López, R. Ramírez-Bon, Low-temperature sol-gel $\mathrm{ZrHfO}_{2}$-PMMA hybrid dielectric thin-films for metal oxide TFTs, J. Non-Cryst. Solids 502 (2018) 152-158.

[14] J. Meza-Arroyo, M.G. Syamala Rao, I. Mejia, M.A. Quevedo- López, R. Ramírez-Bon, Low temperature processing of $\mathrm{Al}_{2} \mathrm{O}_{3}$-GPTMS-PMMA hybrid films with applications to high-performance $\mathrm{ZnO}$ thin-film transistors, Appl. Surf. Sci. 467-468 (2019) 456-461.

[15] S. Choudhary, R.J. Sengwa, ZnO nanoparticles dispersed PVA-PVP blend matrix based high performance flexible nanodielectrics for multifunctional microelectronic device, Curr. Appl. Phys. 18 (2018) 1041-1058.

[16] S. Hammani, A. Barhoum, M. Bechelany, Fabrication of PMMA/ZnO nanocomposite: effect of high nanoparticles loading on the optical and thermal properties, J. Mater. Sci. 53 (2018) 1911-1921.

[17] C. Petchthanasombat, T. Tiensing, P. Sunintaboon, Synthesis of zinc oxide-encapsulated poly(methyl methacrylate)-chitosan core-shell hybrid particles and their electrochemical property, J. Colloid Interface Sci. 369 (2012) 52-57.

[18] S. Khosravi-Gandomani, R. Yousefi, F. Jamali-Sheini, N.M. Huang, Optical and electrical properties of p-type Ag-doped $\mathrm{ZnO}$ nanostructures, Ceram. Int. 40 (2014) 7957-7963.

[19] K. Meeporn, P. Thongbai, Improved dielectric properties of poly(vinylidene fluoride) polymer nanocomposites filled with Ag nanoparticles and nickelate ceramic particles, Appl. Surf. Sci. 481 (2019) 1160-1166.

[20] M. Bușila, V. Musat, T. Textor, B. Mahltig, Synthesis and characterization of antimicrobial textile finishing based on $\mathrm{Ag}: \mathrm{ZnO}$ nanoparticles/chitosan biocomposites, RSC Adv. 5 (2015) 21562-21571.

[21] S. Ji, J. Jang, E. Cho, S.-H. Kim, E.-S. Kang, J. Kim, H.-K. Kim, H. Kong, S.-K Kim, J.-Y. Kim, J.-U. Park, High dielectric performances of flexible and transparent cellulose hybrid films controlled by multidimensional metal nanostructures, Adv. Mater. 29 (2017) 170053.

[22] Q. Sun, B. Qian, K. Uto, J. Chen, X. Liu, T. Minari, Functional biomaterials towards flexible electronics and sensors, Biosens. Bioelectron. 119 (2018) 237-251.

[23] J. Kang, J.B.-H. Tok, Z. Bao, Self-healing soft electronics, Nat. Electron. 2 (2019) 144-150

[24] J. Morgado, A.T. Pereira, A.M. Bragança, Q. Ferreira, S.C.M. Fernandes, C.S.R. Freire, A.J.D. Silvestre, C. Pascoal Neto, L. Alcácer, Self-standing chitosan films as dielectrics in organic thin-film transistors, Express Polym. Lett. 7 (2013) 960-965.

[25] B. Zhou, J. Sun, X. Han, J. Jiang, Q. Wan, Low-voltage organic/inorganic hybrid transparent thin-film transistors gated by chitosan-based proton conductors, IEEE Electron. Device Lett. 32 (2011) 1549-1551.

[26] P. Feng, P. Du, C. Wan, Y. Shi, Q. Wan, Proton conducting graphene oxide/chitosan composite electrolytes as gate dielectrics for new-concept devices, Sci. Rep. 6 (2016) 34065.

[27] A.U. Alam, Y. Qin, S. Nambiar, J.T.W. Yeow, M.M.R. Howlader, N.-X. Hu, M.J. Deen, Polymers and organic materials-based $\mathrm{pH}$ sensors for healthcare applications, Prog. Mater. Sci. 96 (2018) 174-216.

[28] L.M. Bravo-Anaya, K.G. Fernández-Solís, J. Rosselgong, J.L.E. Nano-Rodríguez, F. Carvajal, M. Rinaudo, Chitosan-DNA polyelectrolyte complex: influence of chitosan characteristics and mechanism of complex formation, Int. J. Biol. Macromol. 126 (2019) 1037-1049.

[29] S. Mallakpour, M. Naghdi, Polymer/ $\mathrm{SiO}_{2}$ nanocomposites: production and applications, Prog. Mater. Sci. 97 (2018) 409-447.

[30] K. Kalantari, A.M. Afifi, H. Jahangirian, T.J. Webster, Biomedical applications of chitosan electrospun nanofibers as a green polymer - Review, Carbohydr. Polym. 207 (2019) 588-600.

[31] J. Li, H. Wang, Q. Guo, C. Zhu, X. Zhu, F. Han, H. Yang, B. Li, Multifunctiona coating to simultaneously encapsulate drug and prevent infection of radiopaque agent, Int. J. Mol. Sci. 20 (2019) 2055.

[32] J.K. Ahmed, R.M. Abd Alradha, N.I. Kareem, Molecular interactions of poly (methyl methacrylate) and poly (vinyl alcohol) with chitosan polymer, Acta Sci. Cancer Biol. 3 (2019) 02-10.

[33] K.S. Siddiqi, A. Ur Rahman, T.A. Husen, Properties of zinc oxide nanoparticles and their activity against microbes, Nanoscale Res. Lett. 13 (2018) 141.
[34] N. Ivanova, V. Gugleva, M. Dobreva, I. Pehlivanov, S. Stefanov, V. Andonova Silver nanoparticles as multi-functional drug delivery systems, In: Muhammad Akhyar Farrukh, Nanomedicines, IntechOpen, United Kingdom, 2018.

[35] A.K. Mandal, Silver nanoparticles as drug delivery vehicle against infections, Glob. J. Nano. 3 (2017) 555607.

[36] F. Benyettou, R. Rezgui, F. Ravaux, T. Jaber, K. Blumer, M. Jouiad, L. Motte, J.-C. Olsen, C. Platas-Iglesias, M. Magzoub, A. Trabolsi, Synthesis of silver nanoparticles for the dual delivery of doxorubicin and alendronate to cancer cells, J. Mater. Chem. B 36 (2015) 7145-7310.

[37] J.W. Rasmussen, E. Martinez, P. Louka, D.G. Wingett, Zinc oxide nanoparticles for selective destruction of tumor cells and potential for drug delivery applications, Expert Opin. Drug Deliv. 7 (2010) 1063-1077.

[38] W. Wu, J. Shen, P. Banerjee, S. Zhou, Chitosan-based responsive hybrid nanogels for integration of optical $\mathrm{pH}$-sensing, tumor cell imaging and controlled drug delivery, Biomaterials 31 (2010) 8371-8381.

[39] A. Sirelkhatim, S. Mahmud, A. Seeni, N. Haida, M. Kaus, L.C. Ann, S.K.M. Bakhori, H. Hasan, D. Mohamad, Review on zinc oxide nanoparticles: antibacterial activity and toxicity mechanism, Nano-Micro Lett. 7 (2015) 219-242.

[40] M. Ibănescu, V. Muşat, T. Textor, V. Badilita, B. Mahltig, Photocatalytic and animicrobial $\mathrm{Ag} / \mathrm{ZnO}$ nanocomposites for functionalization of textile fabrics, $\mathrm{J}$ Alloy. Comp. 610 (2014) 244-249.

[41] Y. Zheng, L. Zheng, Y. Zhan, X. Lin, Q. Zheng, K. Wei, Ag/ZnO heterostructure Nanocrystals: synthesis, characterization, and photocatalysis, Inorg. Chem. 46 (17) (2007) 6980-6986.

[42] A. Zaharia, V. Musat, V. Plescan Ghisman, N. Baroiu, Antimicrobial hybrid biocompatible materials based on acrylic copolymers modified with $(\mathrm{Ag}) \mathrm{ZnO} / \mathrm{chi}$ tosan composite nanoparticles, Eur. Polym. J. 84 (2016) 550-564.

[43] L. Spanhel, M.A. Anderson, Semiconductor clusters in the sol-gel process: quantized aggregation, gelation, and crystal growth in concentrated zinc oxide colloids, J. Am. Chem. Soc. 113 (1991) 2826-2833.

[44] E. Valcu Herbei, V. Musat, M. Jank, M. Oertel, T. Leedham, In situ formation of Tantalum Oxide PMMA hybrid dielectric thin films for transparent electronic applications, Adv. Mat. Lett. 6 (2015) 485-491.

[45] D.K. Schroder, Semiconductor Material and Device Characterization, third ed., Wiley, New Jersey, 2006.

[46] G. Duan, C. Zhang, A. Li, X. Yang, L. Lu, X. Wang, Preparation and characterization of mesoporous zirconia made by using a poly (methyl methacrylate) template, Nanoscale Res. Lett. 3 (2008) 118-122.

[47] E. de Souza Costa-Junior, M.M. Pereira, H.S. Mansur, Properties and biocompatibility of chitosan films modified by blending with PVA and chemically crosslinked, J. Mater. Sci. Mater. Med. 20 (2009) 553-561.

[48] M. Kasaai, A review of several reported procedures to determine the degree of $\mathrm{N}$-acetylation for chitin and chitosan using infrared spectroscopy, Carbohydr. Polym. 71 (2008) 497-509.

[49] H. Staroszczyk, K. Sztuka, J. Wolska, A. Wojtasz-Pajak, I. Kołodziejska, Interactions of fish gelatin and chitosan in uncrosslinked and crosslinked with EDC films: FT-IR study, Spectrochim. Acta 117 (2014) 707-712.

[50] S. Ebrahimiasl, A. Zakaria, A. Kassim, S.N. Basri, Novel conductive polypyrrole/zinc oxide/chitosan bionanocomposite: synthesis, characterization, antioxidant, and antibacterial activities, Int. J. Nanomed. 10 (2014) 217-227.

[51] R. Wahab, S.G. Ansari, Y.S. Kim, M.A. Dar, H.S. Shin, Synthesis and characterization of hydrozincite and its conversion into zinc oxide nanoparticles, J. Alloy. Comp. 461 (2008) 66-71.

[52] N.A.A. Aziz, A.A. Bakar, A. Hassan, N. Azmi, Synthesis of chitosan-grafted-poly(methyl methacrylate) with fenton's reagent $\left(\mathrm{Fe} 2+-\mathrm{H}_{2} \mathrm{O}_{2}\right)$ as a redox initiator, Malaysian J. Analytical Sci. 18 (2) (2014) 415-422.

[53] H. Xue, X.L. Xu, Y. Chen, G.H. Zhang, S.Y. Ma, Influence of Ag-doping on the optical properties of ZnO films, Appl. Surf. Sci. 255 (2008) 1806-1810.

[54] E. Peksu, H. Karaagac, Doping and annealing effects on structural, electrical and optical properties of tin-doped zinc-oxide thin films, J. Alloy. Comp. 764 (2018) 616-625.

[55] T. Ivanova, A. Harizanova, T. Koutzarova, B. Vertruyen, Sol-gel nanocrystalline $\mathrm{ZnO}: \mathrm{Ag}$ films: structural and optical properties, Superlattice. Microst. 70 (2014) $1-6$

[56] N.S. Md Ramdzan, Y.W. Fen, N.A.S. Omar, N.A.A. Anas, W.M.E.M.M. Daniyal, S. Saleviter, A.A. Zainudin, Optical and surface plasmon resonance sensing properties for chitosan/carboxyl-functionalized graphene quantum dots thin film, Optik 178 (2019) 802-812.

[57] L.N. Ismail, H. Zulkefle, S.H. Herman, M.R. Mahmood, Influence of doping concentration on dielectric, optical, and morphological properties of PMMA thin films, Ann. Mater. Sci. Eng. 2012 (2012) 1-4.

[58] M. Na, S.W. Rhee, Electronic characterization of Al/PMMA[poly(methyl methacrylate) $] / \mathrm{p}-\mathrm{Si}$ and $\mathrm{Al} / \mathrm{CEP}($ cyanoethyl pullulan)/p-Si structures, Org. Electron. 7 (2006) 205-212.

[59] P.S. Ho, J. Liu, M. Morgen, M. Kiene, J.H. Zhao, Characterization of low dielectric constant materials, in: S.P. Murarka, M. Eizenberg, A.K. Sinha (Eds.), Interlayer Dielectrics for Semiconductor Technologies, Elsevier Inc, London, 2003. 
[60] M.D. Morales-Acosta, M.A. Quevedo-Lopez, B.E. Gnade, R. Ramırez-Bon, PMMA-SiO $\mathrm{S}_{2}$ organic-inorganic hybrid films: determination of dielectric characteristics, J. Sol. Gel Sci. Technol. 58 (2011) 218-224. 